\title{
Modeling of Fuel Cell Hybrid Vehicle in Modelica: Architecture and Drive Cycle Simulation
}

\author{
Sara Sigfridsson ${ }^{1}$ Lixiang Li ${ }^{2} \quad$ Håkan Runvik $^{3} \quad$ Jesse Gohl $^{2} \quad$ Antonin Joly $^{4}$ Kristian Soltesz ${ }^{1}$ \\ ${ }^{1}$ Department of Automatic Control, Lund University, Sweden, \\ sara.sigfridsson.152astudent.lu.se, kristian.soltesz@control.lth.se \\ ${ }^{2}$ Modelon Inc, USA, \{lixiang. li, jesse.gohl\} @modelon.com \\ ${ }^{3}$ Modelon SE, Sweden, hakan. runvik@modelon. com \\ ${ }^{4}$ Modelon KK, Japan, antonin.joly@modelon.com
}

\begin{abstract}
This paper highlights recent development of fuel cell hybrid vehicle (FCHV) models using the Fuel Cell Library (FCL), the Vehicle Dynamics Library (VDL), and Electrification Library (EL) from Modelon. A flexible model architecture is implemented to support physical modeling of such large scale, multi-domain vehicle system. The top-level model consists of a hydrogen fuel cell subsystem with detailed power characteristics and humidification, a hybrid powertrain including battery, converter and electric motor, a vehicle model with chassis and brakes, and a driver model. Drive cycle simulations are performed using these models to analyze system dynamics under different operating conditions.
\end{abstract}

Keywords: fuel cell, hybrid vehicle, vehicle modeling, drive cycle simulation

\section{Introduction}

This section introduces the motivations of the work and provides background about the Fuel Cell Library (FCL), the Vehicle Dynamics Library (VDL), and Electrification Library (EL) used to build the FCHV models.

\subsection{Motivations}

As air pollution and global warming are becoming increasingly severe world-wide and well recognized by the public, hydrogen is gradually gaining attention as a future alternative to traditional fossil fuels in vehicle propulsion system due to its zero emission of pollutants and $\mathrm{CO}_{2}$. As part of the electrification trend in the automotive industry, development of hydrogen fuel cell cars is booming in recent years: most car manufacturers have announced investment in research on FCHV, from component design to system integration. Some have already launched their FCHV products on the market.

While a massive amount of work has been published on detailed modeling, water management and control strategies of vehicle fuel cell stack, few can be found on building flexible and complete FCHV model architecture to evaluate the overall performance of the system, not to mention full drive cycle simulation for FCHV. Such effort, however, is crucial to get more insights into system integration of FCHV and to stimulate innovations in the whole product development cycle. The goal of this paper is to take the first step towards complete FCHV system modeling using well-validated, industrial level Modelica libraries: the FCL, VDL, and EL (see Figure 1).

\subsection{The Fuel Cell Library}

The Fuel Cell Library, or FCL, is a commercial and licensed Modelica ${ }^{\circledR}$ library by Modelon. It is compliant with multiple Modelica tools including JModelica/OCT, ANSYS Simplorer, Ricardo IGNITE and Dymola. It is well suited for component sizing, system design and analysis, control development, and optimization of fuel cell systems for both stationary and mobile applications [1][2][3]. Solid Oxide (SOFC) and Proton Exchange Membrane (PEMFC) fuel cells are included as examples in the library with expandable templates for other types of fuel cells. The library also contains a large number of ready-to-use components for modeling chemical reactions in pre-reforming reactors and fluid distribution in fuel/air manifolds.

\subsection{The Vehicles Dynamic Library}

The Vehicle Dynamics Library, or VDL, is another commercial and licensed Modelica ${ }^{\circledR}$ library by Modelon. It is intended for vehicle dynamics analysis related to mechanical design and control design of automotive chassis. The library can be used to analyze partial and complete vehicles. Models are designed in a way that is similar to the structure of real vehicle assemblies. The focus is on chassis, wheels, driver, and road but basic models for e.g. engines, transmissions, drivetrains, and brakes are supplied to offer full vehicle modeling and simulation capability in a single environment. 


\subsection{The Electrification Library}

The Electrification Library is a new commercial and licensed Modelica ${ }^{\circledR}$ library from Modelon. The library provides a number of typical components needed when modeling electrified systems including vehicles (like full electric, battery hybrid, and fuel cell vehicles), aircraft, auxiliary power systems, etc. This includes batteries, machines, converters, and loads. It also includes thermal implementations of the components in order to support full thermal management modeling. The library uses a flexible architecture for the components to allow any level of fidelity to be used for any portion of the components as needed throughout the design process.

\begin{tabular}{|c|c|}
\hline $\mathrm{F}$ & uelCell \\
\hline (i) & Information \\
\hline$>$ & Interfaces \\
\hline 口 & Examples \\
\hline$>$ & Burners \\
\hline$N$ & FlowResistances \\
\hline$>$ 幽 & HeatExchangers \\
\hline 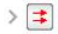 & HeatTransfer \\
\hline$>\mathbb{H}$ & Icons \\
\hline$>0$ & Internal \\
\hline 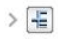 & Manifolds \\
\hline$>\infty$ & Media \\
\hline$>\phi$ & Membranes \\
\hline 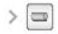 & Pipes \\
\hline$>0$ & Pumps \\
\hline$>\rightarrow$ & Sources \\
\hline$>\equiv$ & Stacks \\
\hline$>0$ & Reactions \\
\hline$>0$ & Reactors \\
\hline (1) & Sensors \\
\hline$>\square$ & SubComponents \\
\hline$>0$ & Volumes \\
\hline $\mathbf{z}$ & Walls \\
\hline
\end{tabular}

\begin{tabular}{|c|c|}
\hline (2) VehicleDynamics & Electrification \\
\hline$>$ (i) Information & $>$ (i) Information \\
\hline$>\square$ Examples & $>\square$ Examples \\
\hline$>$ Atmospheres & $\checkmark \pm$ Batteries \\
\hline$>A$ Drivers & $>$ Interfaces \\
\hline$>$ Grounds & $>\mathrm{T}$ Templates \\
\hline$>$ Scenes & $>\underline{V}$ Experiments \\
\hline$\checkmark$ Vehicles & $>\square$ CoreBattery \\
\hline (i) Information & $>\square$ ElectricalAdaptor \\
\hline$>$ Interfaces & $>\square$ ThermalAdaptor \\
\hline$>\mathrm{T}$ Templates & $>\square$ MechanicalAdaptor \\
\hline$>\underline{V}$ Experiments & $>$ Controller \\
\hline$>$ Brakes & $>\square$ Examples \\
\hline$>$ Chassis & $>D$ Machines \\
\hline$>$ ControlUnits & $>$ Converters \\
\hline$>$ Dashboards & $>\square$ Loads \\
\hline$>\uplus$ Powertrains & $>$ Common \\
\hline$>\square$ Examples & $>4$ Electrical \\
\hline$>$ Migration & $>0$ Thermal \\
\hline$>\odot$ RealTime & $>$ II Icons \\
\hline$>\boldsymbol{x}$ Utilities & \\
\hline $\begin{array}{l}\text { Difl World } \\
\text { DIR }\end{array}$ & \\
\hline & \\
\hline
\end{tabular}

Figure 1. Content in the FCL, VDL, and EL.

\section{System Model}

This section of the paper outlines the top-level system architecture and key subsystems in the FCHV model. They are viewed as a proof-of-concept to build a largescale, multi-domain system model for analysis of the system dynamics of an FCHV in drive cycles, which will support various levels of model fidelity and will facilitate control development in the future. Hence, no customer-proprietary data was involved in the parameterization of the models. The vehicle model was based on existing sedan component models from VDL. Most of the other parameters were based on open product information of the Toyota Mirai [4][5] or estimated from the authors' experience.

\subsection{Top-level System Architecture}

The top-level FCHV system model consists of a fuel cell subsystem, a hydrogen tank, a hybrid powertrain, a vehicle model, a driver model, a controller and other system level information (weather, road, drive cycle data etc.). The control bus is used to pass control signals to various subsystems while expandable connectors of different domains, e.g. electrical, fluid, mechanical etc., allows physical coupling of different subsystems. The architecture shown in Figure 2 represents the topology of the FCHV system. All the subsystems are replaceable, which supports future development of more detailed models. In VDL, there are templates that place the powertrain in the vehicle model, however, we decided to expose the hydrogen tank, fuel cell stack, and powertrain on the top-level in the case of FCHV for easier access to these key subsystems.

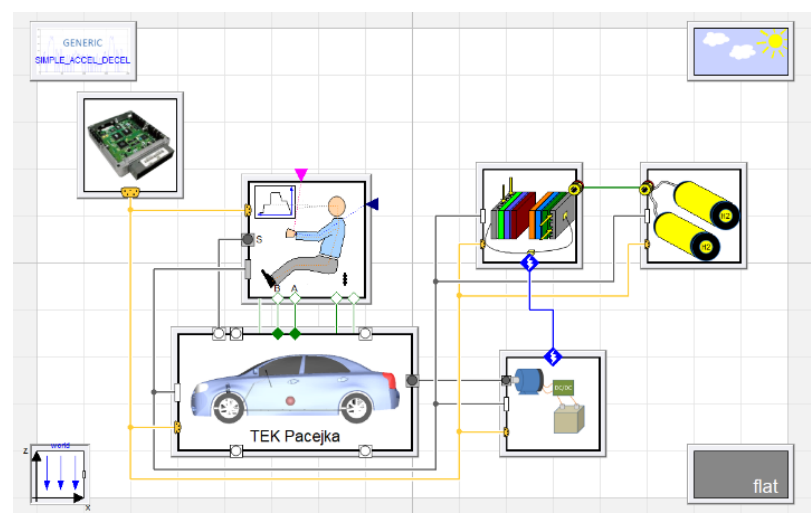

Figure 2. Top-level architecture of the Hydrogen fuel cell hybrid vehicle model.

\subsection{Fuel Cell Subsystem}

The fuel cell subsystem mainly consists of a proton exchange membrane fuel cell (PEMFC) stack, a humidifier, a heat exchanger and several fluid machines for the air flow, hydrogen flow, and coolant flow, as shown in Figure 3.

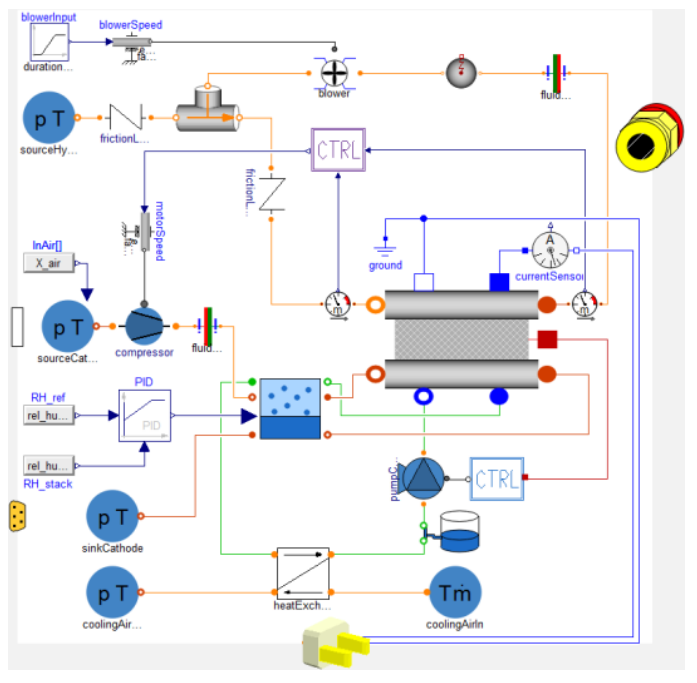

Figure 3. Hydrogen fuel cell subsystem.

On the anode side, excessive hydrogen at the exit is circulated to improve efficiency and to avoid using after-burner. On the cathode side, the air flow rate is controlled using a P-controller based on the consumption of hydrogen in the anode and 
stoichiometric calculation. The cooling water pump is controlled by a PID controller based on the stack temperature.

In order to keep the cells hydrated, incoming air from the atmosphere goes through a humidifier before reaching cathode channel. The humidifier makes use of the produced water coming out from the cathode to maintain the relative humidity of the air supply at the desired level. More details on the humidifier are discussed in Section 2.2.3.

The stack model has a hierarchical structure and includes a cooling channel, anode, cathode and the cell membrane. The anode and cathode channels are modeled as lumped volumes with condensation effects. Gases are transported into the membrane which handles calculations of power characteristics and water transport across the membrane. Geometric based, distributed model can be further developed by adopting existing templates of discretized membrane and flow channels from FCL.

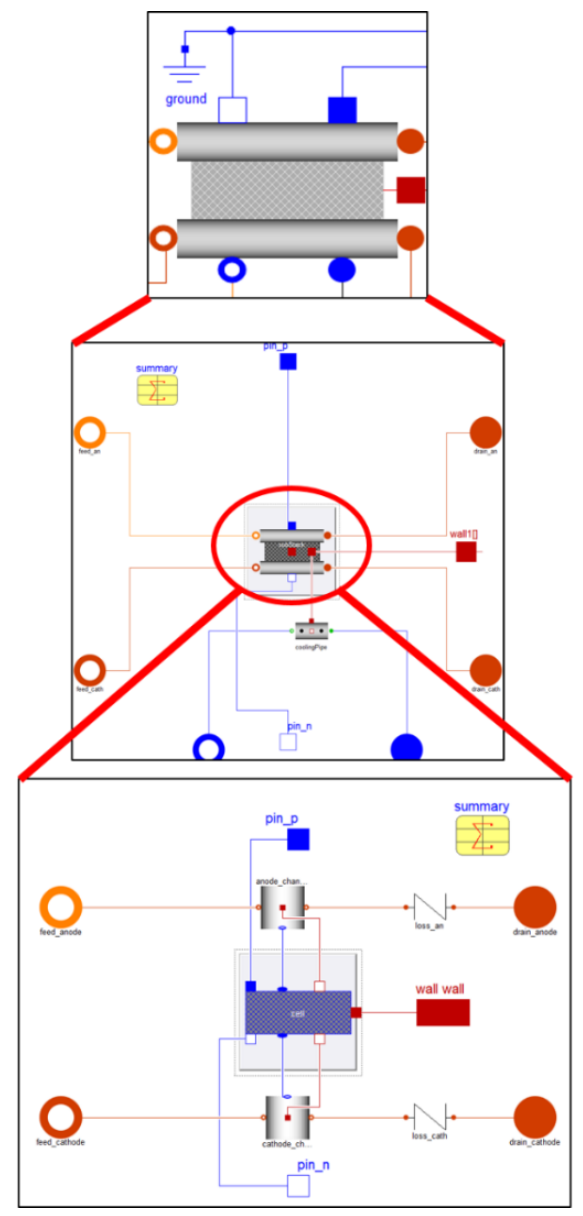

Figure 4. Hierarchical structure of the fuel cell stack.

\subsubsection{Power Characteristics}

The open circuit voltage of the stack is obtained by the Nernst equation:

$$
E=-\frac{\Delta G_{f}{ }^{0}}{2 F}+\frac{R T}{2 F}\left(\frac{p_{H_{2}} p_{O_{2}}{ }^{0.5}}{p_{H_{2} O}}\right)
$$

where the $\Delta G_{f}{ }^{0}[\mathrm{~J} / \mathrm{mol}]$ is the change in molar Gibbs free energy of formation of hydrogen fuel cell at standard pressure; $T[\mathrm{~K}]$ is the temperature of the cell; $p_{\mathrm{H}_{2}}, p_{\mathrm{H}_{2}}$ and $p_{\mathrm{H}_{2} \mathrm{O}}[\mathrm{Pa}]$ are partial pressure of $\mathrm{H}_{2}, \mathrm{O}_{2}$ and $\mathrm{H}_{2} \mathrm{O}$ vapor. $R$ is the ideal gas constant and $F$ is the Faraday constant.

Activation loss, Ohmic loss, and concentration loss are implemented using the following models respectively [6]:

$$
\begin{gathered}
\Delta V_{\text {act }}=\frac{R T}{2 \alpha F} \ln \left(\frac{i+i_{n}}{i_{0}}\right) \\
\Delta V_{\text {Ohmic }}=i r \\
\Delta V_{\text {conc }}=m \exp (n i)
\end{gathered}
$$

$i_{0}\left[\mathrm{~A} / \mathrm{m}^{2}\right]$ is the exchange current density; $i_{n}$ is the fuel crossover equivalent current density; $i$ is the cell current density; $r\left[\Omega \cdot \mathrm{m}^{2}\right]$ is the area-specific resistance dependent on the thickness and water content of the membrane [7]; $m[\mathrm{~V}]$ and $n\left[\mathrm{~m}^{2} / \mathrm{A}\right]$ are empirical constants for concentration loss. The open circuit voltage with irreversibility is obtained as

$$
V=E-\Delta V_{\text {act }}-\Delta V_{\text {ohmic }}-\Delta V_{\text {conc }}
$$

The polarization curve of a single cell and the total power curve of the FC stack model used in drive cycle simulations are shown in Figure 5 and Figure 6 respectively.

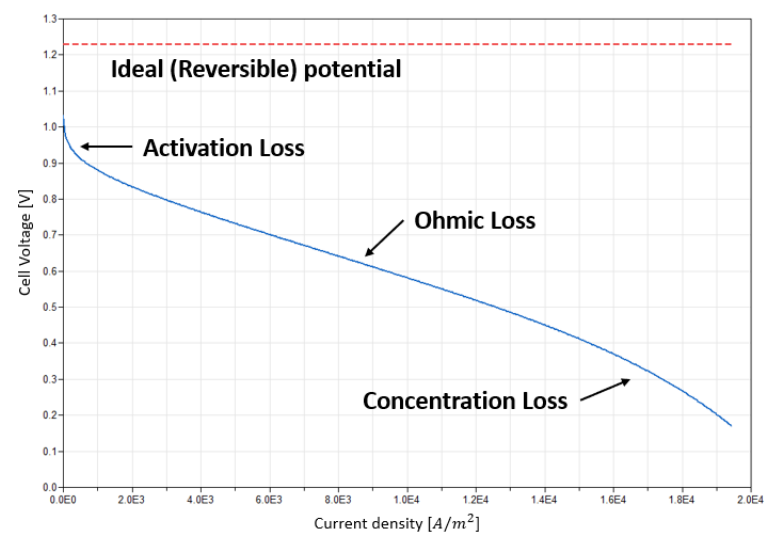

Figure 5. Polarization curve of a single cell at $80 \mathrm{degC}$.

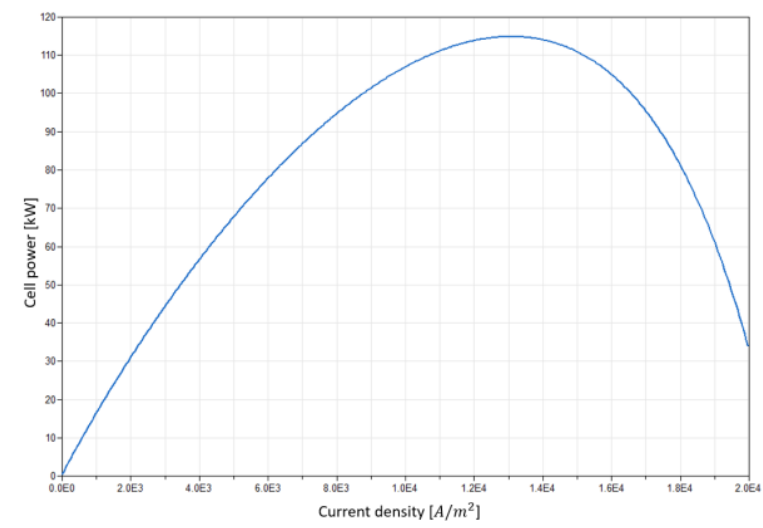

Figure 6. Total power of the FC stack at $80 \operatorname{degC}$. 
Voltage efficiency of the fuel cell can be defined as

$$
\eta_{\text {voltage }}=\frac{E}{E^{0}}=\frac{E}{1.229 \mathrm{~V}}
$$

which is a measurement of irreversible losses of the fuel cell. Although the total stack power peaks at a current density of $1.3 \mathrm{e} 4 \mathrm{~A} / \mathrm{m}^{2}$, the corresponding voltage efficiency is less than $40 \%$. So, the current drawn from the stack need be limited by the hybrid drivetrain control algorithm to avoid significant irreversible losses, which is discussed in Section 2.3.

\subsubsection{Water transport across the Cells}

Back diffusion and electro-osmotic drag are both considered for water transport across the membrane[7]:

$$
\begin{gathered}
N_{\text {osmotic }}=n_{d} \frac{i}{F} \\
N_{\text {diff }}=D_{w}\left(\frac{c_{c a t h}-c_{a n}}{t_{m}}\right) \\
N_{\text {membrane }}=N_{\text {diff }}-N_{\text {osmotic }}
\end{gathered}
$$

where $N_{\text {osmotic }}\left[\mathrm{mol} /\left(\mathrm{s} \cdot \mathrm{m}^{2}\right)\right]$ is water flow from anode to cathode due to electro-osmotic drag; $N_{\text {diff } f}$ is water flow from cathode to annode caused by back diffusion; $D_{w}\left[\mathrm{~m}^{2} / \mathrm{s}\right]$ is the diffusion coefficient of water; $c_{\text {cath }}\left[\mathrm{mol} / \mathrm{m}^{3}\right]$ and $c_{a n}$ are the water concentration at the cathode and anode; $t_{m}[\mathrm{~m}]$ is the thickness of the membrane. The water mass flow rate [kg/s] across the membrane for a single cell can be obtained by

$$
\dot{m}_{\text {water }}=18.01528 \cdot N_{\text {membrane }} \cdot A_{\text {cell }}
$$

\subsubsection{Humidifier}

The humidifier model, shown in Figure 7, assumes ideal mixing and instantaneous thermodynamic equilibrium.

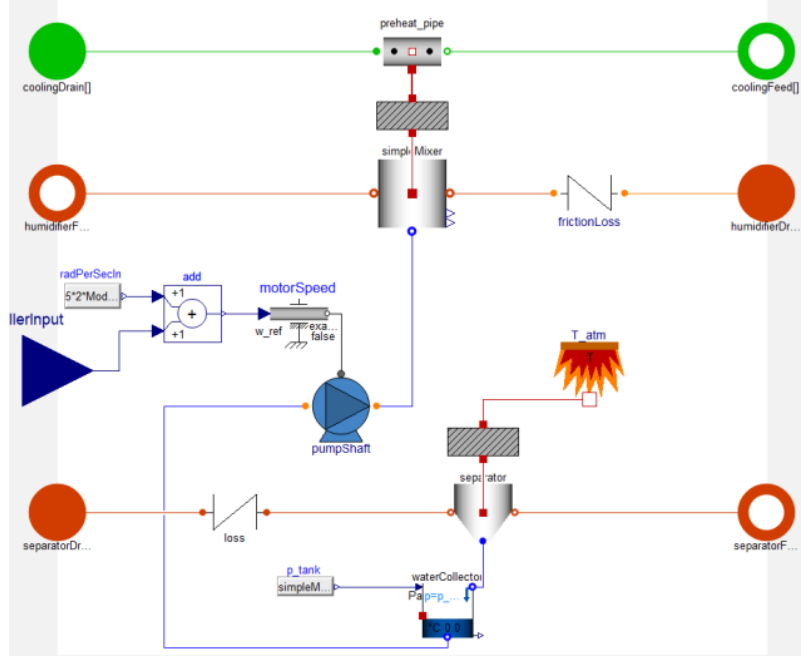

Figure 7. Humidifier model assuming ideal mixing.
The exhaust gas out of the cathode is cooled by the ambient in the separator so that water can be condensed and collected (flow route at the bottom of Figure 7). Then the condensed water is sent to the ideal mixer to humidify the supplied air. The humid air is pre-heated by the cooling water coming out of the stack, in order to maintain the stack temperature better and to increase the saturation vapor pressure of water.

This model can be replaced by diffusion-based membrane humidifier model [8][9][10] in the future.

\subsection{Hybrid drivetrain}

The hybrid drivetrain is constructed in a similar configuration to Toyota Mirai [11]: both the fuel cell and the battery are connected to DC/DC converters to match the maximum motor voltage. While Mirai has an AC motor and an inverter, the Modelica model uses a DC motor model because the high-frequency dynamics are not of interest in this study.

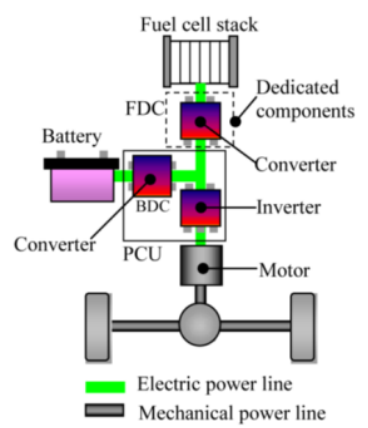

(a)

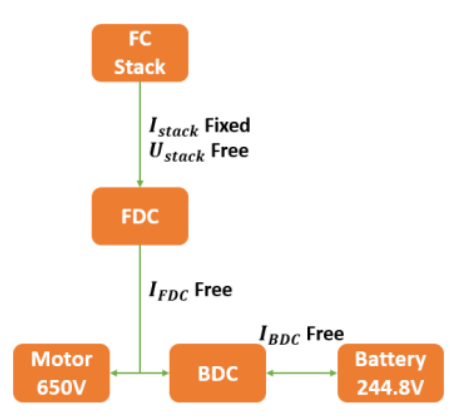

(b)
Figure 8. (a) Hybrid drivetrain of TOYOTA Mirai (picture taken from [11]). (b) Schematic plot of the hybrid drivetrain implemented in the Modelica model

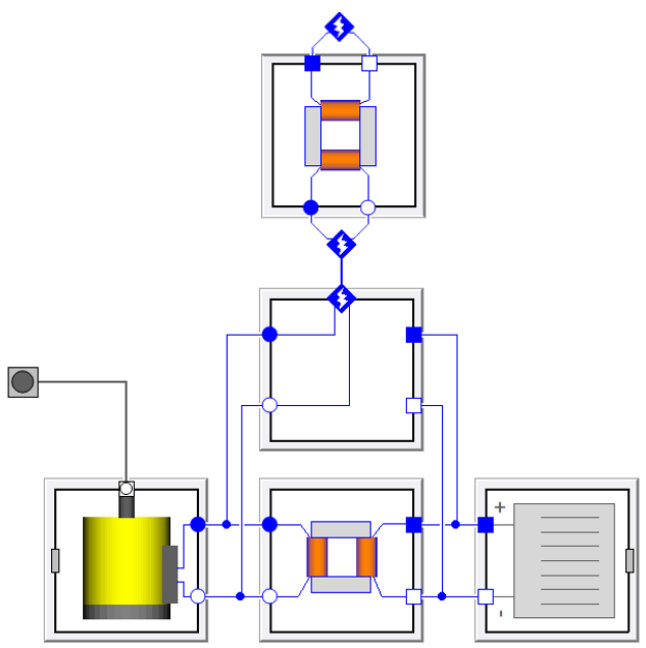

Figure 9. Hybrid drivetrain including battery, battery converter, fuel cell converter, and DC motor.

Mathematical formulation and data of the $\mathrm{Ni}-\mathrm{MH}$ battery $(1.6 \mathrm{~V}, 6.5 \mathrm{Ah}$ per cell) model can be found in [12], hence not to repeat here. The state of charge (SOC) of the battery and the motor current demand $I_{c m d}$ are used to determine the current drawn from the 
fuel cell. When the demand is above the maximum current of the fuel cell or if the SOC is below a threshold $\mathrm{SOC}_{\text {switch }}$, the fuel cell will work at maximum current; otherwise, the fuel cell will directly drive the motor at the demanded current. A low-pass filter is added to remove high frequency oscillation in the control signal for fuel cell current.

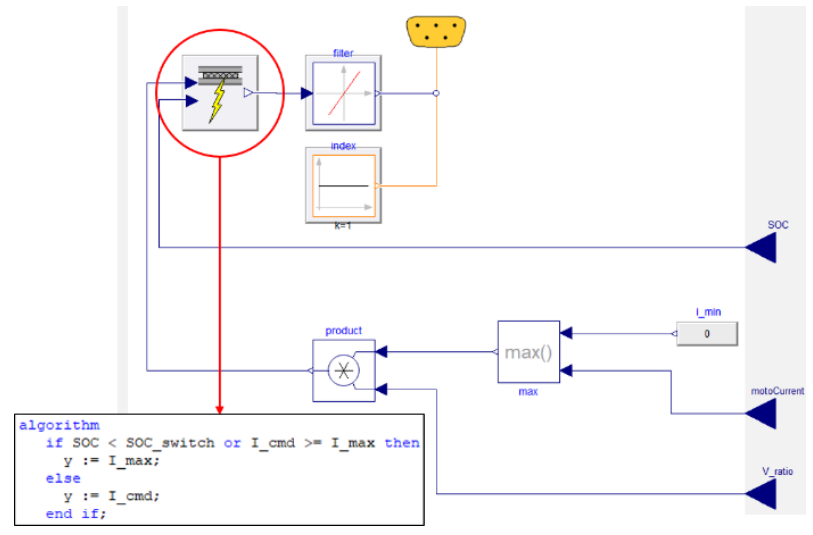

Figure 10. The control algorithm for the fuel cell. I_cmd is the motor current demand, I_max is the maximum current of the fuel cell and $y$ is the control signal of current drawn from the fuel cell.

\subsection{Vehicle Model}

The fuel cell, drivetrain, vehicle, and hydrogen storage models are the focus at the top level of the system model, see Figure 2. The vehicle is based on standard component models from the VDL including the chassis, drivetrain, and brakes. These standard models are used in the template shown in Figure 11. Also shown in this figure is an expansion of the chassis model which is a standard implementation included in VDL of a sedan with Pacejka tire models and tabular elasto-kinematic front and rear suspension models. The drivetrain and brake models are also standard passenger sedan implementations included in VDL. The drivetrain is a front-wheel, two-wheel drive implementation. The brake model was a powerassisted, four-wheel disk brake implementation. The only customization needed in this case was a template with a connector at the top level for the mechanical 3D rotational connection to the motor. With the template created all the components were simply selected for use in the complete vehicle model.

\subsection{Driver and Drive cycle}

The driver model is also a standard model included in VDL that follows a desired vehicle speed trace defined by a drive cycle profile. While a number of standard cycles are available, the profile used for this test was the 600-s supplemental federal test procedure, SC03 cycle as shown in Figure 13. The driver model produces the accelerator and brake commands necessary to follow this cycle. These pedal commands are combined in the motor controller to produce the motor torque command and the foundation brakes provide supplemental braking to the motor torque.

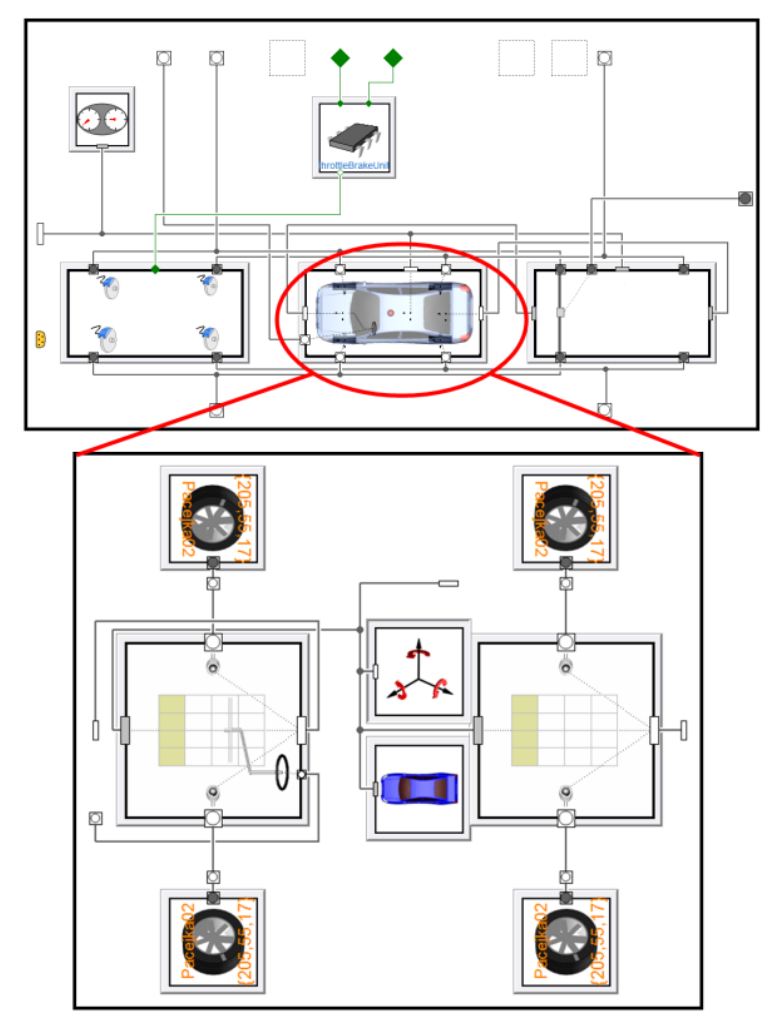

Figure 11. Vehicle model template from the VDL.

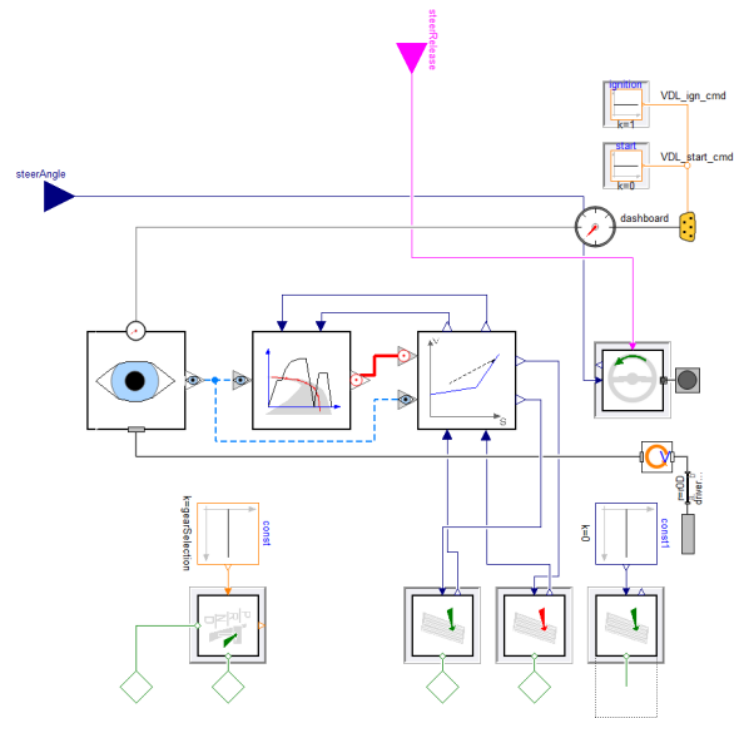

Figure 12. Driver model from the VDL.

\section{Drive Cycle Simulations}

The SC03 drive cycle speed profile, shown in Figure 13 , is used for verification of the FCHV system model. The cycle represents a $5.8 \mathrm{~km}$ drive that lasts for $596 \mathrm{~s}$ (600 $\mathrm{s}$ in the simulation, zero speed for the last $4 \mathrm{~s}$ ) with an average speed of $34.8 \mathrm{~km} / \mathrm{h}$, the maximum speed of $88.2 \mathrm{~km} / \mathrm{h}$. The system model includes all the 
subsystems shown in Figure 2 except the high-pressure hydrogen storage tank and valve subsystem.

The simulations are performed in Dymola 2018 FD01 on a Dell Precision M2800 laptop with $2.8 \mathrm{GHz}$ CPU and 16GB RAM.

\subsection{The Parameterization}

Key parameters in the model are listed in Table 1-4.

Table 1. Parameters of the fuel cell membrane.

\begin{tabular}{|l|l|}
\hline Parameters and unit & Value \\
\hline Number of cells (in series) & 370 \\
\hline FC Stack weight $[\mathrm{kg}]$ & 56 \\
\hline Exchange current density $i_{0}\left[\mathrm{~A} / \mathrm{m}^{2}\right]$ & 0.12 \\
\hline Fuel crossover current density $i_{n}\left[\mathrm{~A} / \mathrm{m}^{2}\right]$ & 15 \\
\hline Empirical constant $m[\mathrm{~V}]$ & $3 \mathrm{e}-4$ \\
\hline Empirical constant $n\left[\mathrm{~m}^{2} / A\right]$ & $3.2 \mathrm{e}-4$ \\
\hline Membrane thickness $[\mu \mathrm{m}]$ & 100 \\
\hline Active cell area $\left[\mathrm{m}^{2}\right]$ & 0.05 \\
\hline Parameters for Ohmic loss from $[7]$ & \\
\hline
\end{tabular}

Table 2. Parameters of the hybrid drivetrain [11][12].

\begin{tabular}{|l|l|}
\hline Parameters and unit & Value \\
\hline Number of cells (in series) in the battery & 204 \\
\hline Cell nominal voltage [V] & 1.2 \\
\hline Cell nominal capacity [Ah] & 6.5 \\
\hline Motor maximum power [kW] & 113 \\
\hline Motor peak torque [N·m] & 335 \\
\hline Motor maximum speed [rad/s] & 340 \\
\hline Motor nominal voltage [V] & 650 \\
\hline DC/DC converter efficiency & $90 \%$ \\
\hline
\end{tabular}

Table 3. Parameters of the vehicle model [4].

\begin{tabular}{|l|l|}
\hline Parameters and unit & Value \\
\hline Curb weight $[\mathrm{kg}]$ & 1850 \\
\hline Wheelbase $[\mathrm{m}]$ & 2.7813 \\
\hline Tires: P215/55R17 & \\
\hline
\end{tabular}

Table 4. Operation condition of the FC stack.

\begin{tabular}{|l|l|}
\hline Parameters and unit & Value \\
\hline FC stack $T_{\text {ref }}[\mathrm{degC}$ ] for coolant controller & 60 \\
\hline Hydrogen inlet pressure [bar] & 2 \\
\hline Air inlet pressure [bar] & 1.013 \\
\hline $\begin{array}{l}\text { Reference relative humidity of air for } \\
\text { humidifier controller }\end{array}$ & 0.9 \\
\hline
\end{tabular}

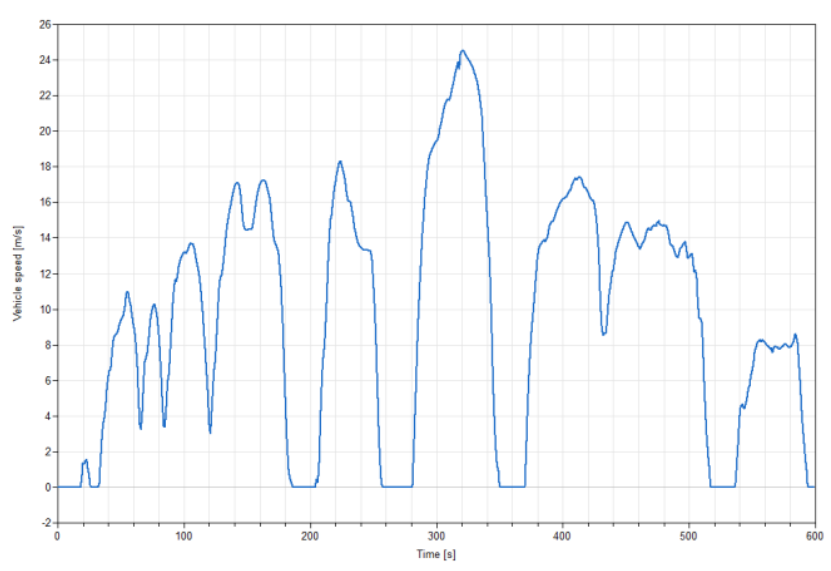

Figure 13. Speed profile of $\mathrm{SC} 03$ cycle.

\subsection{Results and discussions}

The results obtained from the $\mathrm{SCO} 3$ drive cycle simulations can be found in Figure 14 - Figure 17. Dynamics of the system at different ambient air condition is analyzed and discussed in this section.

In the simulations, Hydrogen is supplied at $25 \mathrm{degC}$ and 2 bar. Ambient air comes in at fixed atmospheric pressure but various temperatures $(5,25$ and $38 \mathrm{degC})$ to represent different seasons. The air gets compressed and humidified before it is fed to the cathode. The compressor draws a different amount of air from the ambient according to the consumption of hydrogen in the fuel cell (the demanded current load equivalently). Pressures in the anode and cathode flow channels can be found in Figure 14.

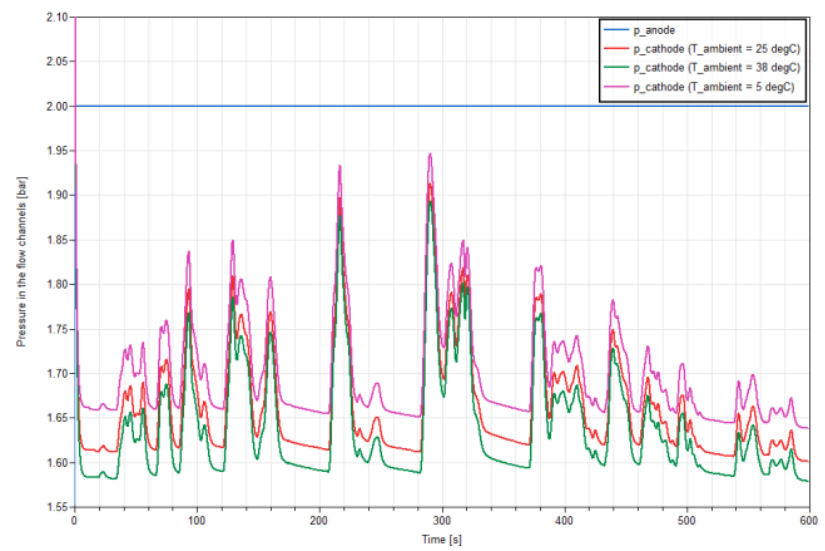

Figure 14. Pressure in the anode channel (Blue) and in the cathode channel (Purple: $T_{\text {ambient }}=5 \mathrm{degC}$, Red: $T_{\text {ambient }}=25 \mathrm{degC}$, Green: $\left.T_{\text {ambient }}=38 \mathrm{degC}\right)$.

The power output of the FC stack and battery, as well as the battery SOC, are plotted in Figure 15. SOC of the battery is initialized at 0.6. In general, the battery responds much faster to electric load than the fuel cell does. When the vehicle accelerates hard, the motor draws current from both the battery and the fuel cell. When the electric load decreases, the fuel cell has a lag in response, so the generated electricity is stored in the battery, resulting in an increase in SOC. 

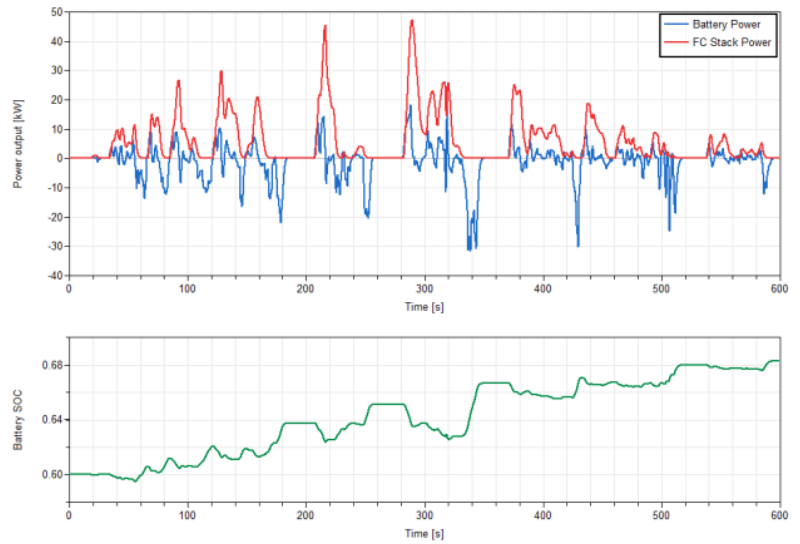

Figure 15. Power outputs and battery SOC during the SC03 cycle with $T_{\text {ambient }}=25 \mathrm{dgC}$.

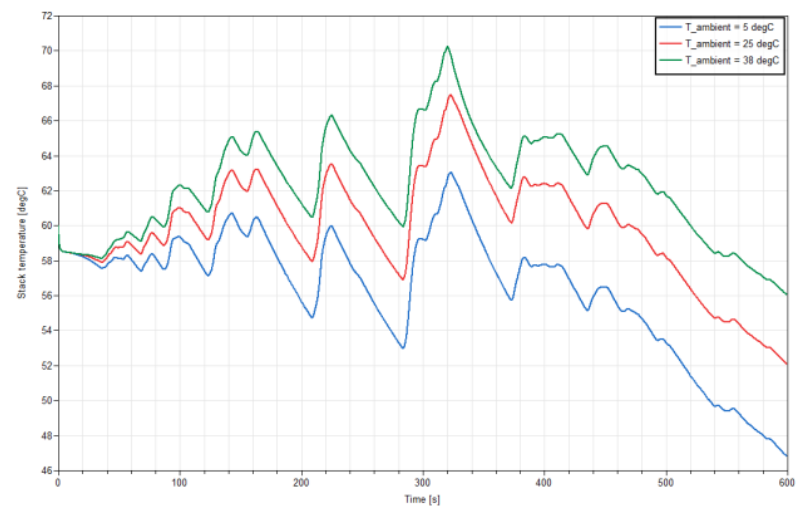

Figure 16. Stack temperatures during the $\mathrm{SC} 03$ cycle under different ambient air temperatures: Blue $-5 \mathrm{degC}$, Red $-25 \operatorname{degC}$, Green $-38 \operatorname{degC}$.

Temperature control of the FC stack is challenging, as illustrated in Figure 16. The stack temperature is initialized at $60 \operatorname{degC}$ and varies according to the current demand. In $290 \mathrm{~s}$ to $310 \mathrm{~s}$, the vehicle accelerates from $0 \mathrm{~km} / \mathrm{h}$ to $88.2 \mathrm{~km} / \mathrm{h}$, which put a large load on the fuel cell. As a result, the stack temperature increases rapidly by about $10 \operatorname{degC}$. When the stack power output is too low, for example in the last $100 \mathrm{~s}$ in the drive cycle, the stack temperature drops significantly.

Figure 16 also compares stack temperatures during the drive cycle with different ambient air temperature. It shows that the stack temperature is sensitive to the ambient air temperature. More sophisticated coolant pump control strategies and an additional air pre-heater are needed to better maintain the stack temperature.

The computational performance of the FCHV system model can be seen in the CPU time plot in Figure 17. The 600-s drive cycle simulation is finished in 390s CPU time, which is less than $2 / 3$ of the real time. Hence, the FCHV system model as it stands is real-time capable and it will be of great interest for controller development and HIL application. Further improvement of computation speed can be achieved as demonstrated in [2].

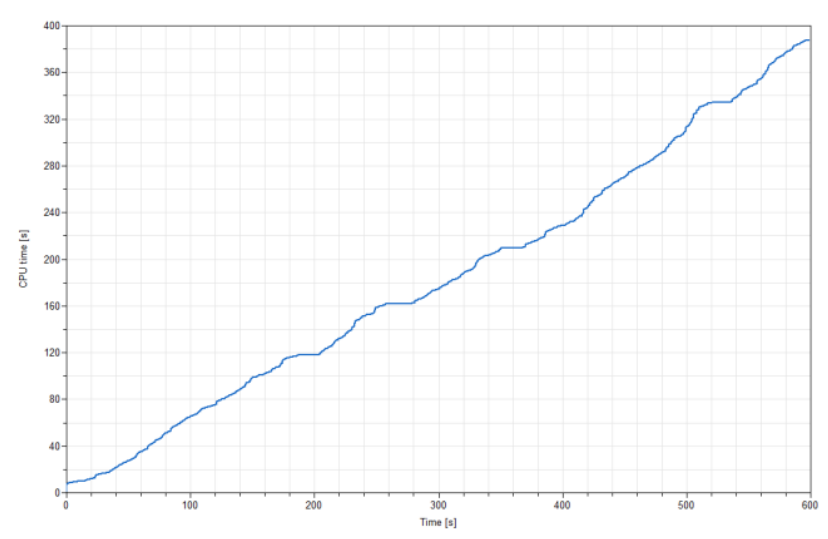

Figure 17. CPU time plot of the SO03 cycle simulation.

\section{Conclusions and Future Development}

A flexible model architecture for Hydrogen FCHV has been developed using a coordinated suite of Modelica libraries: FCL, VDL, and EL. It covers both physical modeling (across thermal, fluid, electrical, and mechanical domains) and controls modeling. Drive cycle simulations of the $\mathrm{SCO} 3$ cycle are performed using the FCHV system model for verification. The model is found to be real-time capable. Such simulations demonstrate the use of sophisticated Modelica libraries to enable multi-physical modeling of the full FCHV system for future design, control, and optimization purposes.

With the flexible architecture developed in this work, subsystem or component models of higher fidelity can be developed and plugged into the system as a future improvement, for example:

- Discretized FC stack with cross-flow channels

- Diffusion-based membrane humidifier

- High-pressure Hydrogen tank with pressure regularization valve and its control system

- Hydrogen recirculation using an ejector.

Beyond dynamic simulations and analysis of the FCHV, the use of such full FCHV system model for other applications is also worth exploring:

- Study of temperature and water management of the fuel cell under real drive cycle

- Component selection and system integration

- Exploration of hybrid drivetrain configurations

- Controller development and optimization.

\section{References}

[1] Andersson, D., Åberg, E., Eborn, J., Yuan J. and Sundén, B. Dynamic Modeling of a Solid Oxide Fuel Cell System in Modelica. Modelica 2011 Conference, Dresden, Germany, pp.593-602, Mar. 20-22, 2011.

[2] Fröjd, K., Axelsson, K., Torstensson, I., Åberg, E., Osvaldsson, E., Dolanc, G., Pregelj, B., Eborn, J. and Pålsson, J. Development of a Real-Time Fuel Processor Model for HIL Simulation. Modelica 2014 Conference, Lund, Sweden, pp.675-682, Mar. 10-12, 2014. 
[3] Åberg E., Pålsson, J., Fröjd K., Axelsson K., Dolanc G., Pregelj B. HIL simulations of a Real-Time Fuel Processor Model. 5th European PEFC \& H2 Forum 2015, Lucerne, Switzerland, June 30-July 3, 2015.

[4] TOYOTA 2017 Mirai Product Information. https://ssl.toyota.com/mirai/assets/core/Docs/Mirai\%20 Specs.pdf

[5] Nonobe, Y. Development of the fuel cell vehicle Mirai. IEEE Transactions on Electrical and Electronic Engineering, 12, pp. 5-9, 2017

[6] Dicks, A.L. and Rand, D.A., Fuel cell systems explained, 2nd edition. John Wiley \& Sons, 2018.

[7] Pukrushpan, J.T., Modeling and control of fuel cell systems and fuel processors. PhD Thesis, Ann Arbor, Michigan, USA: University of Michigan, 2003

[8] Chen, D. and Peng, H., A thermodynamic model of membrane humidifiers for PEM fuel cell humidification control. Journal of dynamic systems, measurement, and control, 127(3), pp.424-432, 2005.

[9] Chen, D., Li, W. and Peng, H., An experimental study and model validation of a membrane humidifier for PEM fuel cell humidification control. Journal of Power Sources, 180(1), pp.461-467, 2008.

[10] Solsona, M., Kunusch, C. and Ocampo-Martinez, C., Control-oriented model of a membrane humidifier for fuel cell applications. Energy conversion and management, 137, pp.121-129, 2017

[11] Hasuka, Y., Sekine, H., Katano, K., and Nonobe, Y., Development of Boost Converter for MIRAI, SAE Technical Paper, 2015-01-1170, 2015

[12] Tremblay, O., Dessaint, L.A. and Dekkiche, A.I., A generic battery model for the dynamic simulation of hybrid electric vehicles. Vehicle Power and Propulsion Conference, 2007. IEEE, pp. 284-289, 2007. 